\title{
Imaging methods for surgical revascularization in patients with moyamoya disease: an updated review
}

\author{
Lanxin $\mathrm{Du}^{1,2} \cdot$ Hanyu Jiang ${ }^{3} \cdot$ Jin $\mathrm{Li}^{4} \cdot$ Ting Duan $^{3} \cdot$ Chenyun Zhou ${ }^{2} \cdot$ Feng $\mathrm{Yan}^{2,5}(\mathbb{C}$
}

Received: 8 August 2020 / Revised: 20 June 2021 / Accepted: 24 June 2021 / Published online: 21 August 2021

(c) The Author(s) 2021

\begin{abstract}
Neuroimaging is crucial in moyamoya disease (MMD) for neurosurgeons, during pre-surgical planning and intraoperative navigation not only to maximize the success rate of surgery, but also to minimize postsurgical neurological deficits in patients. This is a review of recent literatures which updates the clinical use of imaging methods in the morphological and hemodynamic assessment of surgical revascularization in patients with MMD. We aimed to assist surgeons in assessing the status of moyamoya vessels, selecting bypass arteries, and monitoring postoperative cerebral perfusion through the latest imaging technology.
\end{abstract}

Keywords Moyamoya disease $\cdot$ Revascularization $\cdot$ Neuroimaging $\cdot$ Angiography $\cdot$ Ultrasound

\begin{tabular}{|c|c|c|c|}
\hline \multicolumn{2}{|c|}{ Abbreviations } & PCA & Posterior cerebral artery \\
\hline MMD & Moyamoya disease & EC-IC & Extracranial-intracranial \\
\hline MMVs & Moyamoya vessels & $\mathrm{CBF}$ & Cerebral blood flow \\
\hline IAS & Atherosclerotic stenosis & CBV & Cerebral blood volume \\
\hline CHS & Cerebral hyper-perfusion syndrome & MTT & Mean transit time \\
\hline ICA & Internal carotid artery & TTP & Time to peak \\
\hline $\mathrm{ECA}$ & External carotid artery & PSV & Peak-systolic velocity \\
\hline STA & Superficial temporal artery & EDV & End-diastolic velocity \\
\hline \multirow{3}{*}{\multicolumn{2}{|c|}{ MCA }} & MFV & Mean flow volume \\
\hline & & RI & Resistance index \\
\hline & & CVR & Cerebrovascular reserve \\
\hline \multirow[t]{2}{*}{$\triangle$} & \multirow{2}{*}{$\begin{array}{l}\text { Feng Yan } \\
\text { yan_feng@scu.edu.cn }\end{array}$} & CVRC & Cerebrovascular reserve capacity \\
\hline & & OEF & Oxygen extraction fraction \\
\hline \multirow[t]{5}{*}{1} & Department of Ultrasound \& Key Laboratory of Birth & $\mathrm{CMRO}_{2}$ & Cerebral metabolic rate of oxygen \\
\hline & \multirow{2}{*}{$\begin{array}{l}\text { Defects and Related Diseases of Women and Children } \\
\text { of Ministry of Education, West China Second }\end{array}$} & IVWI & Intracranial vessel wall imaging \\
\hline & & DSC-MRI & Dynamic susceptibility contrast MRI \\
\hline & & ASL-MRI & Arterial spin labeling MRI \\
\hline & $\begin{array}{l}\text { Renmin South Road, } 610041 \text { Chengdu, Sichuan, } \\
\text { People's Republic of China }\end{array}$ & BOLD-fMRI & Blood oxygen level-dependent functional \\
\hline 2 & $\begin{array}{l}\text { Department of Ultrasound, West China Hospital of Sichuan } \\
\text { University, } 37 \text { Guoxue Street, } 610041 \text { Chengdu, Sichuan, } \\
\text { People's Republic of China }\end{array}$ & FLAIR-MRI & $\begin{array}{l}\text { Fluid-attenuated inversion-recovery MR } \\
\text { imaging }\end{array}$ \\
\hline \multirow[t]{2}{*}{3} & \multirow{2}{*}{$\begin{array}{l}\text { Department of Radiology, West China Hospital of Sichuan } \\
\text { University, } 37 \text { Guoxue Street, } 610041 \text { Chengdu, Sichuan, } \\
\text { People's Republic of China }\end{array}$} & SPECT & $\begin{array}{l}\text { Single-photon emission computed } \\
\text { tomography }\end{array}$ \\
\hline & & PET & Positron emission tomography \\
\hline \multirow[t]{2}{*}{4} & \multirow{2}{*}{$\begin{array}{l}\text { Department of Neurosurgery, West China Hospital } \\
\text { of Sichuan University, } 37 \text { Guoxue Street, } 610041 \text { Chengdu, } \\
\text { Sichuan, People's Republic of China }\end{array}$} & ICG-VAG & Indocyanine green video-angiography \\
\hline & & TCCS & $\begin{array}{l}\text { Transcranial color-coded duplex } \\
\text { sonography }\end{array}$ \\
\hline \multirow[t]{2}{*}{5} & \multirow{2}{*}{$\begin{array}{l}\text { Clinical Ultrasound Imaging Drug Research Lab, West } \\
\text { China Hospital of Sichuan University, } 37 \text { Guoxue Street, } \\
610041 \text { Chengdu, Sichuan, People's Republic of China }\end{array}$} & TCD & Transcranial Doppler \\
\hline & & CEUS & Contrast-enhanced ultrasound \\
\hline
\end{tabular}




\section{Introduction}

Moyamoya disease (MMD) is an uncommon cerebrovascular disease characterized by progressive stenosis of the terminal portion of the internal carotid artery (ICA) and its main branches [37]. The disease is associated with the development of dilated, fragile collateral vessels, termed as moyamoya vessels (MMVs). The hemorrhagic and ischemic types are the two main clinical manifestations. The diagnosis of MMD mainly depends on neurological symptoms and imaging findings. Neurosurgical revascularization is considered the mainstay treatment in symptomatic patients to increase intracranial cerebral blood flow (CBF) and cerebrovascular reserve (CVR) [40]. The stenotic degree of the ICA, the compensatory ability of the collateral circulation, the selection of bypass area and the matching of bypass vessels, and the monitoring of postoperative cerebral perfusion are the key points that surgeons care about, which cannot be separated from the support of neuroimaging. In recent years, the concepts of "flow-controlled bypass" and "precised bypass" have been put forward, aiming to improve the cerebral perfusion in preoperatively ischemic areas, reduce the ineffective bypass, and reduce the cerebral hyper-perfusion syndrome (CHS) caused by excessive bypass.

In this review, we will provide an update on the morphological and hemodynamic assessment of common neuroimaging techniques used in surgical revascularization in MMD and introduce other emerging imaging methods, such as indocyanine green video-angiography and ultrasonography, which are simple and practical for intraoperative assessment. This review compares the benefits and drawbacks of various imaging techniques in the perioperative period of MMD from different perspectives, so as to provide a reference for the selection of surgeons, in order to provide the success rate of revascularization and obtain satisfactory long-term outcomes.

\section{Method}

The PubMed, Ovid, Embase, and Cochrane databases were searched over a 20-year period between 2001 to 2021 using the Boolean search term ("moyamoya disease" OR "moyamoya syndrome" OR "MMD") AND ("revascularization" OR "bypass surgery" OR "STA-MCA bypass" OR "direct surgery" OR "indirect surgery") AND ("imaging" OR "Computed tomography" OR "Digital subtraction angiography" OR "Magnetic resonance imaging" OR "Singlephoton emission computed tomography" OR "Positron emission tomography" OR "Fluorescence imaging" OR "Ultrasonography"). References of each manuscript were checked for papers that were of potential relevance to our review. Two authors (D.L.X. and Y.F.) independently identified articles using the above search criteria. Relevant articles on the application of imaging technologies in moyamoya disease in the past decade were mainly included. For the decade 2001-2011, high-quality articles highly relevant to the content of this review were mainly included. The full text of each selected article was obtained and analyzed.

\section{Digital subtraction angiography (DSA)}

DSA is considered the gold standard in diagnosing MMD [44]. Owing to its high spatial and temporal resolution, this method plays an irreplaceable role in assessing the stenoocclusion of the terminal ICA, and the patency of anastomosis. Moreover, DSA is the best choice to observe the establishment of collateral circulation, which is crucial for the decision of treatment strategies and the evaluation of the neo-angiogenesis status after surgery [14, 15, 43]. Compared with other imaging modalities, DSA has superior diagnostic value for detecting concomitant diseases such as intracranial aneurysm (Fig. 1), arteriovenous malformation, and subarachnoid hemorrhage in patients with MMD [4, 42, 50].

Quantitative color-coded parametric DSA (QDSA, Syngo iFlow) is an emerging DSA technique which provides objective perfusion parameters like time-to-peak (TTP), mean transit time (MTT), and ratios of area under the curve (AUC ratio) to assess hemodynamic changes of a certain artery after bypass surgery. Although it does not provide information on cerebral parenchyma perfusion, it is useful for measuring blood supply from the internal and external carotid artery systems $[8,9]$.

However, DSA is not recommended for pediatric patients or patients in poor conditions, due to its invasiveness, time consumption, and need for anesthesia.

\section{Computed tomography}

\section{Computed tomography angiography (CTA)}

CTA can clearly show the circle of the Willis, as well as the anterior, middle, and posterior cerebral arteries and their main branches, providing an important diagnostic basis for occlusive vascular lesions. Because of its short acquisition time and fast image postprocessing, CTA is the first choice in emergency cases. In MMD, ischemic stroke can be diagnosed as early as $2 \mathrm{~h}$ after onset. Cortical surface imaging with CTA can be used to depict the number and distribution of MCA cortical arteries (M4) which are the main recipient arteries in STA-MCA bypass surgery [66]. Compared with MRA, CTA has the advantage to display the vascular status of the extracranial segment of STA (Fig. 2a-d) [35]. However, CTA has limitations in showing MMVs with small 

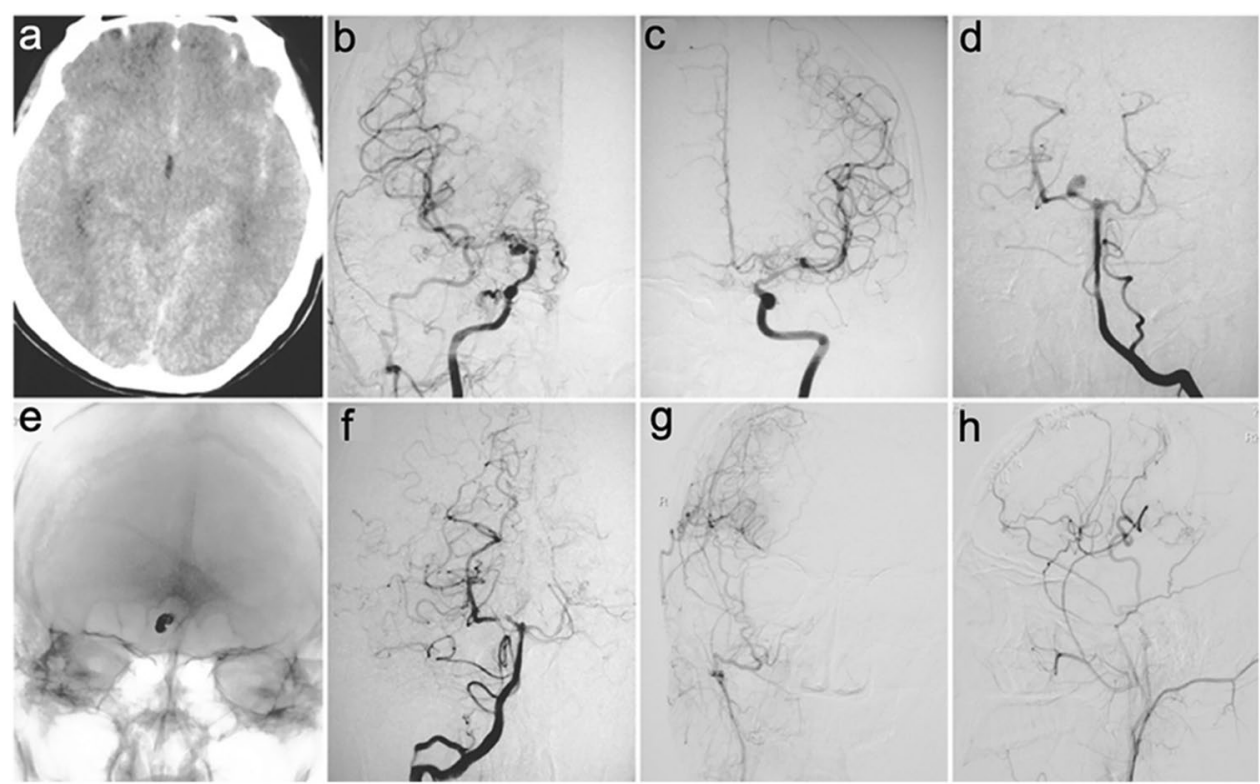

Fig. 1 A 40-year-old MMD patient with severe explosive headache was found to have a saccular aneurysm by DSA. The aneurysm was occluded by coil embolization immediately after DSA. Right STAMCA bypass combined with EDMS was performed 1 month after SAH ictus. a CT scan revealed SAH in the longitudinal fissure, Sylvian fissure, and quadrigeminal cistern. $\mathbf{b}$ and $\mathbf{c}$ Bilateral ICA angi-

ography studies showing MMD with Suzuki Stage III. d Vertebral angiography study showing a saccular aneurysm at the P1/P2 junction of the right PCA. e and $\mathbf{f}$ Follow-up vertebral angiography studies showing complete obliteration of the aneurysm. $\mathbf{g}$ and $\mathbf{h}$ ECA angiography studies showing Matsushima Grade A collateral compensation supplied by the anastomosis [50]

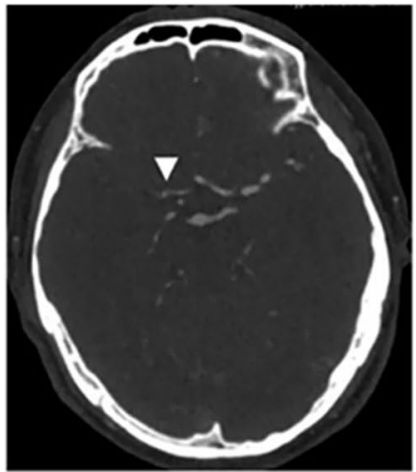

a

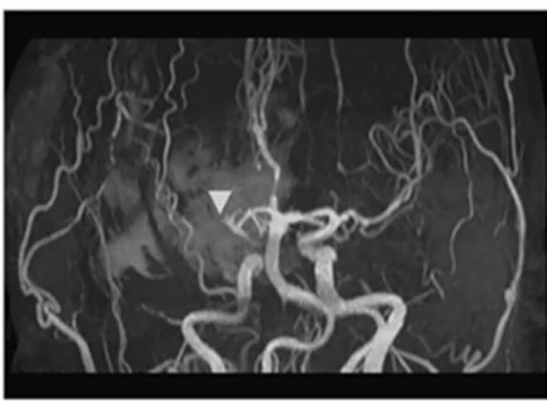

e

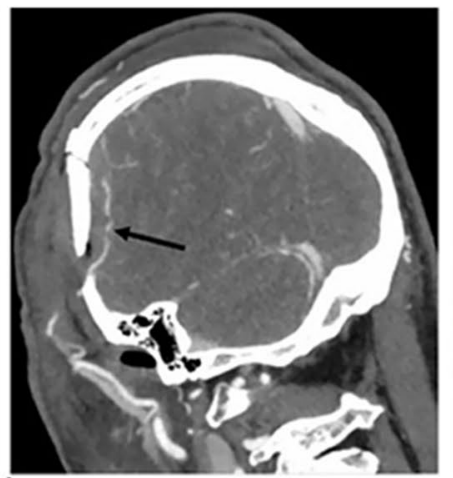

$\mathrm{b}$

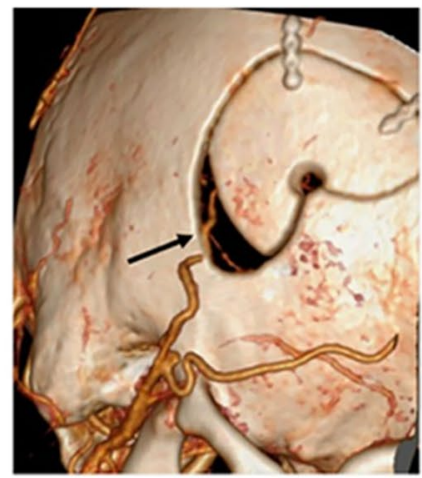

C

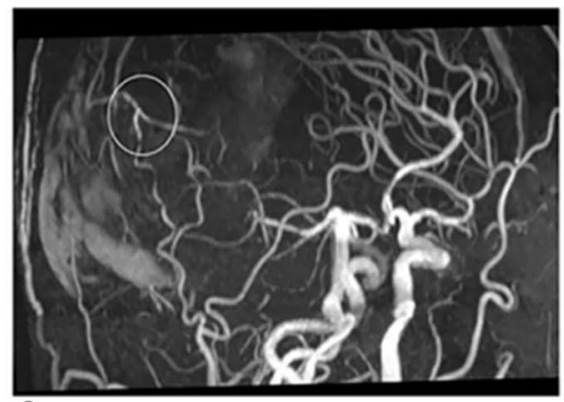

$\mathrm{f}$

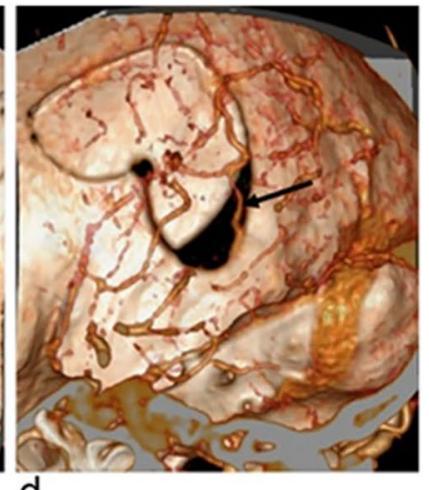

d

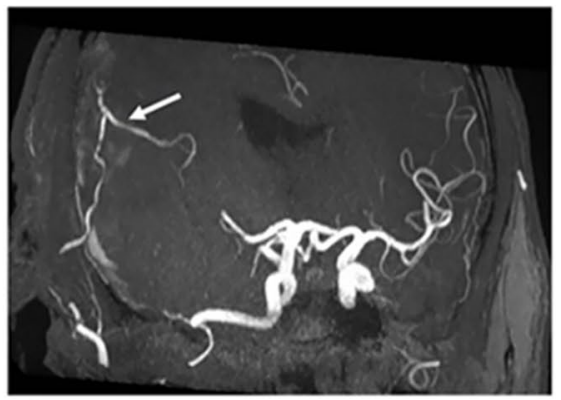

g
Fig. 2 A 55-year-old patient underwent right-side STA-MCA bypass surgery. a Preoperative CTA and e preoperative MRA show the occlusion of the right MCA (arrowheads). b, c, $\mathbf{d}$ Postoperative CTA show that the right STA (black arrows) entered the cranium through the bone defect area of the temporal region. $\mathbf{f}$ and $\mathbf{g}$ Postoperative MRA clearly showed the anastomosis (circled area) and the distal branch of the MCA (white arrow). Image courtesy of Dr. Hanyu Jiang, Department of Radiology, West China Hospital 
calibers $(<3 \mathrm{~mm})$ and its resolution is lower than that of DSA. CTA may also be interfered by motion artifacts.

Dynamic 3D- and 4D-CTA can simultaneously display subtle angio-architectural features and vascular flow patterns, providing information on ongoing vascular changes as well as accurate spatial delineation of cerebrovascular pathologies [3]. However, the clinical practice of 4D-CTA is restricted by its high total radiation dose.

\section{Computed tomography perfusion (CTP)}

CTP has the advantages of short acquisition time and high spatial resolution, so it is generally the first choice to measure the changes of cerebral hemodynamics after surgery. Among the parameters extracted from the time intensity curve, the changes of TTP and MTT are the most sensitive ones in the early postoperative period [7], followed by $\mathrm{CBF}$, which is also the matter of great concern to surgeons. CBF is closely related to bypass patency and can directly reflect the degree of blood supply recovery. The change in CBV is complicated, affected by the ability of different automatic regulation processes involving arterial, capillary, venous, and parenchymal components [10]. Previous studies have shown that in patients with ischemic MMD treated either with STAMCA bypass surgery or surgery involving multiple burr holes, the postoperative MMT and TTP values are significantly shortened, CBF is significantly increased, while
CBV might increase or decrease (Fig. 3) [7, 10, 65]. In a recent retrospective clinical study of 57 patients with hemorrhagic MMD, the CBV appeared to decrease and be relatively stable in the chronic phase after revascularization with varying degrees of MTT and TTP shortening, and no significant change in CBF [29]. Bypass surgery is of great value in the treatment of ischemic MMD, but it is still controversial in hemorrhagic MMD. Therefore, a larger sample size, multicenter prospective study with longer follow-up time is needed to confirm the difference in hemodynamic changes between the two stroke subtypes after bypass surgery.

\section{Magnetic resonance imaging}

\section{Magnetic resonance angiography (MRA)}

MRA provides a noninvasive, radiation-free alternative to DSA and CTA for evaluating bypass patency and can be used to measure arterial caliber to predict the development of surgical collaterals [68]. Among MRA techniques, 3D TOF-MRA is the most commonly used technique for cerebral artery imaging with high spatial resolution and signalto-noise ratio (SNR), as well as very thin slice thickness. In terms of showing the intracranial segment of the STA and EC-IC bypass anastomosis, TOF-MRA is at least as good as CTA or even better than CTA (Fig. 2e-f). However, as TOFMRA is velocity-dependent, the turbulent flow at stenosis
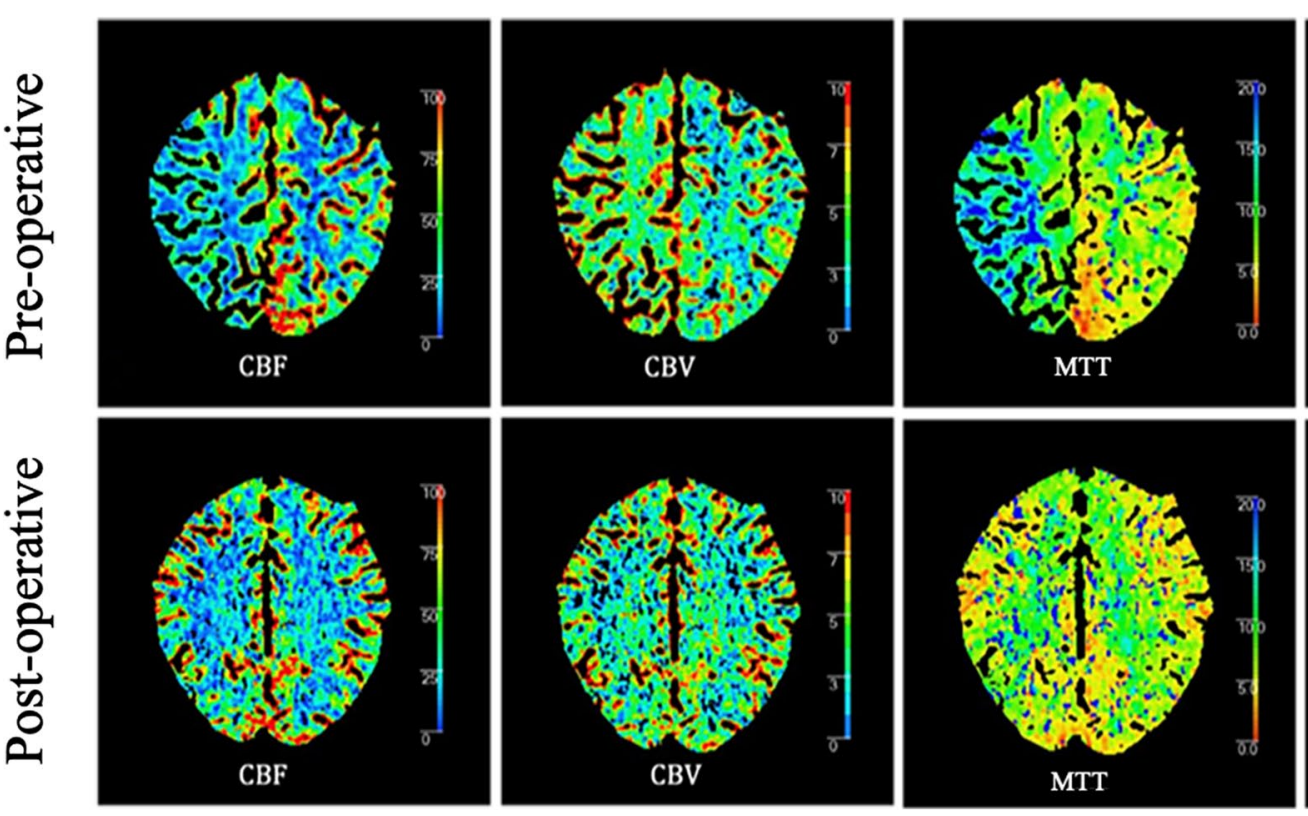
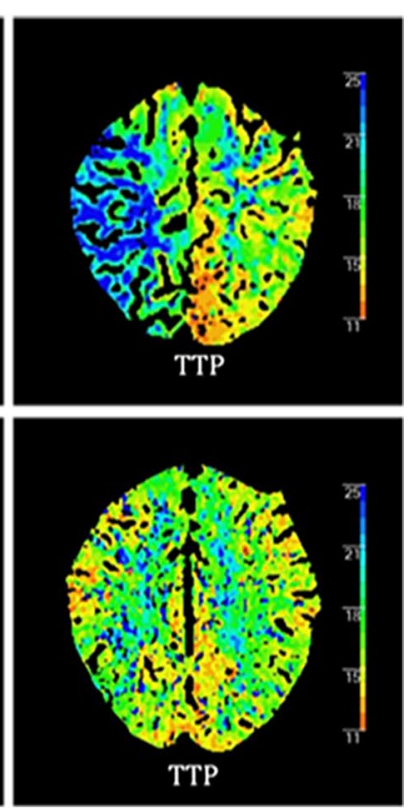

Fig. 3 Hemodynamic changes of a 23-year-old female underwent STA-MCA bypass revascularization in the right hemisphere. Preoperative CTP (the upper row) shows that in the right MCA area, CBF was significantly decreased; MTT and TTP were significantly pro- longed, while CBV was slightly increased. Six months after surgery, postoperative CTP (the bottom row) shows increased CBF, reduced CBV, shortened MTT and TTP in the same region. Image courtesy of Dr. Hanyu Jiang, Department of Radiology, West China Hospital 
a

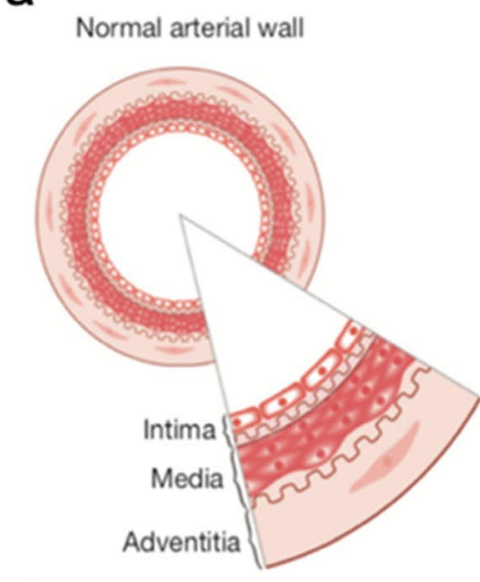

d

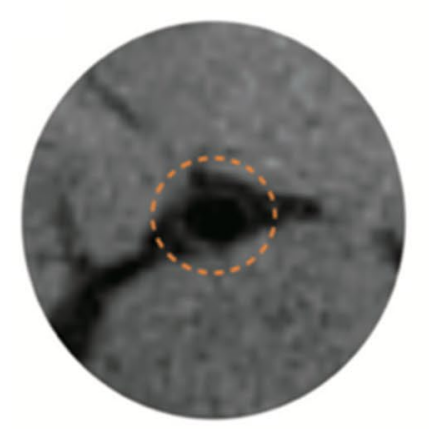

b

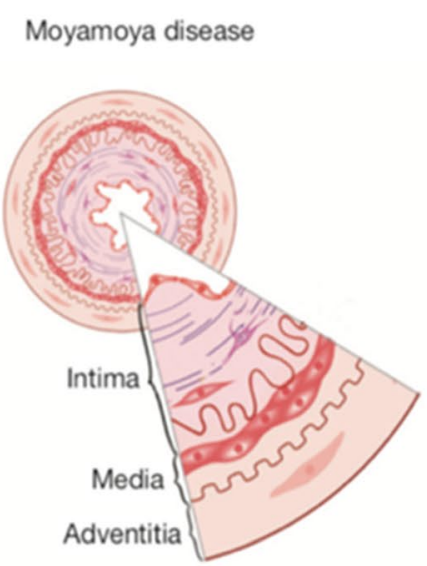

e

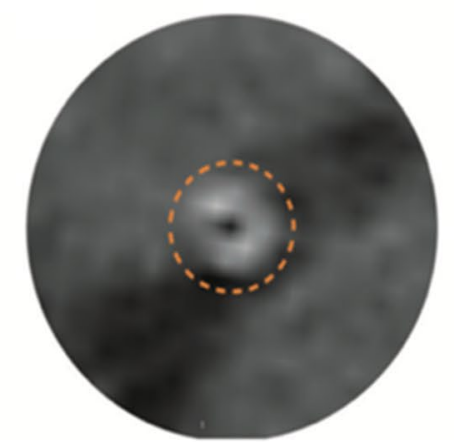

C

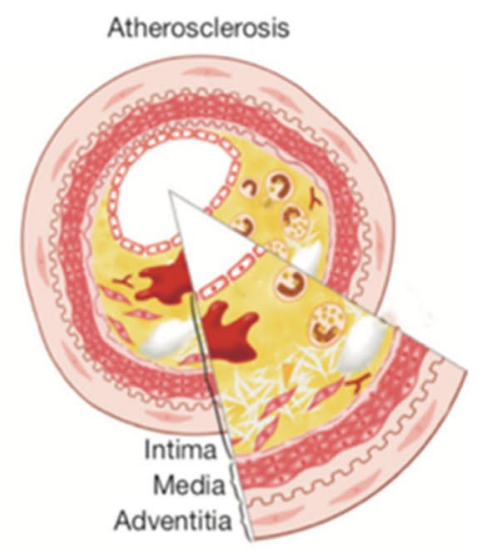

f
Fig. 4 Pathological mechanism and IVWI manifestations of moyamoya disease and atherosclerosis. a, $\mathbf{d}$ Pathologic and IVWI findings of normal arterial lumens. b, e Compared with normal arterial wall, the affected artery wall in MMD is characterized by the thickness of intima and the atrophy of media, with homogeneous signal intensity and concentric vessel wall thickening on IVWI. c, f In atherosclerosis, the main etiology of arterial stenosis is the build-up of atherosclerotic plaque and the lipid deposition under the endothelium, with eccentric and heterogeneous vessel wall thickening on IVWI [73] may cause phase dispersion and signal loss. It was shown that TOF-MRA is inferior to CTA in revealing trepanation bypass segments and overestimates focal pseudo-occlusive lesions in this area [6]. TOF-MRA also tends to overestimate ICA stenosis compared with contrast-enhanced MRA [71].

\section{Intracranial vessel wall imaging (IVWI)}

IVWI is an adjunct to conventional MRA and has great potential in morphological assessment of MMD revascularization. Based on high-resolution MRI (HR-MRI), IVWI has been proved to be effective to differentiate MMD from intracranial atherosclerotic stenosis (Fig. 4) [60, 73, 82]. On IVWI images, MMD tends to have homogeneous signal intensity enhancement and concentric vessel wall thickening, while intravascular atherosclerotic stenosis (IAS) shows eccentric and heterogeneous vessel wall thickening. Compared with IAS, the outer diameters of stenotic ICA and MCA are smaller in patients with MMD. High-grade arterial wall enhancement on IVWI may associate with the progression of angiopathy and a high risk of ischemic infarction [30, 58]. However, the difference in vessel wall enhancement between early and late angiographic stages of MMD remains to be further investigated [47]. More research is also needed to evaluate the value of IVWI in differentiating ischemic or hemorrhagic strokes caused by moyamoya disease.

\section{Ultrahigh field intensity magnetic resonance}

Although 1.5-T and 3.0-T MRI are commonly used, ultrahigh field (7.0-T) MRI is a promising neuroimaging technique for the evaluating of MMD especially the risk of hemorrhage. The advantages of TOF at 7.0-T include the increased SNR, longer T1 relaxation times augmenting the vessel-tissue contrast, and inherently hyperintense arterial vasculature at higher field strengths [34, 62, 63]. There was no significant difference between 3.0-T MRI and 7.0-T MRI in depicting the main intracranial arteries, but 7.0-T MRI could excellently delineate the collateral network pathways 
in MMD and is better correlated with Suzuki's stage [12]. Susceptibility-weighted imaging (SWI) and TOF-MRA fusion images in 7.0-T MRI help to improve the detection of bleeding points in hemorrhagic MMD, and screening these patients will help to better assess the risk of intracranial hemorrhage [63]. At present, 7.0-T MRI has not been widely used in clinic, and more studies are needed to confirm its value in surgical reconstruction of hemorrhagic MMD.

\section{Fluid-attenuated inversion-recovery MR imaging (FLAIR-MRI)}

The "Ivy sign," leptomeningeal high signal intensity, is an MMD-specific feature on fluid-attenuated inversion-recovery MR imaging, indicating slow flow of engorged pial vasculature toward leptomeningeal collaterals and "misery perfusion" areas. Studies showed that the decrease of the "ivy sign" on FLAIR-MRI after surgery is related to the improvement of cerebral hemodynamics and clinical symptoms, while de novo "ivy sign" may predict early postoperative CHS [22, 28, 31].

\section{Dynamic susceptibility contrast MRI (DSC-MRI)}

DSC-MRI is currently one of the most used MR perfusion imaging techniques to quantify cerebral hemodynamic changes by neurosurgeons. DSC-MRI can help to select candidates for MMD intervention and predict the outcome and risk of surgery. In the studies of Ishii et al. [24, 25], the MTT measured by DSC-MRI may depict the small amelioration of arterio-genesis as early as 2-4 weeks after indirect bypass surgery, far earlier than other imaging modalities. The degree of MTT delay shortening was positively correlated with the surgical effect. However, the disadvantages of DSC-MRI are the need for a contrast agent, insufficient quantitative reliability, and long resolution time [55].

\section{Arterial spin labeling MRI (ASL-MRI)}

ASL-MRI uses magnetically labeled inflowing blood as an endogenous tracer to estimate brain perfusion at the tissue level [72, 83], especially suitable for pediatric patients with MMD [5, 18, 56]. Pulsed arterial spin labeling (PASL), continuous arterial spin labeling (CASL), and pseudo-continuous arterial spin labeling (pCASL) are three labeling methods, among which pCASL is the most superior based on high labeling efficacy and signal to noise. Recent studies suggest that ASL-MRI is well correlated with DSC-MRI, CTP, PET, and SPECT in mapping CVR and CBF [16, 17, $51,52,70,83]$. Studies have demonstrated the clinical significance of ASL-MRI in evaluation postoperative hemodynamic dysfunction $[18,49]$. Compared with preoperative cerebral perfusion, there was no significant increase in
ASL signal in the bypass area, suggesting that there was still hypoperfusion. When ASL signal increases more than $100 \%$, researchers should be alert to the risk of CHS (Fig. 5).

However, ASL-MRI has an inherent deficiency, caused by its imaging mechanism. For instance, the measured CBF could be underestimated due to the long arterial transit times (ATTs) in steno-occlusive arterial segments and collateral pathways. Under these circumstances, the use of multi-delay or long-label-long-delay algorithms in ASL-MRI could help improve the accuracy of CBF assessments with satisfactory SNR [13, 70]. Interestingly, highintensity signals of arterial transit artifacts (ATA) caused by ATTs could be in turn, used to depict the collateral flow in morphology [39, 84]. Overall, ASL-MRI is a promising noninvasive alternative for evaluating the hemodynamics of MMD when nuclear medical imaging methods are not available, but its limitations such as weak signal intensity, low image resolution, and poor repeatability limit it from becoming a standalone imaging method for clinical cerebral perfusion assessments.

\section{Blood oxygen level-dependent functional MRI (BOLD-fMRI)}

BOLD-fMRI is a brain mapping technique using deoxyhemoglobin in the blood vessels as an endogenous contrast agent to produce functional activation maps. BOLDfMRI is widely used to monitor CVR and neurovascular coupling changes and assess surgical efficacy following revascularization [59, 61]. Previous BOLD-fMRI studies often change the concentration of end-expiratory carbon dioxide to map CVR with breath-holding or $\mathrm{CO}_{2}$ inhalation techniques [11, 20]. Liu et al. [41] proposed using resting-state BOLD data to map CVR, which can avoid gas inhalation or breath-holding. The global BOLD signal in the frequency range of $0.02-0.04 \mathrm{~Hz}$ provides the best estimation of the spontaneous fluctuation of blood $\mathrm{CO}_{2}$ concentration, relative to that in other frequency bands. BOLD-fMRI holds future potential in becoming a routine examination in the pre- and post-operative evaluation of MMD patients especially for pediatric patients. However, how to improve the stability and repeatability of BOLD imaging is a major concern in clinical practice.

\section{Nuclear medical imaging techniques}

\section{Single-photon emission computed tomography (SPECT)}

SPECT is considered the reference standard technique for CBF perfusion assessments $[16,64]$. As radioactive tracers, ${ }^{99} \mathrm{mTc}-\mathrm{ECD},{ }^{99} \mathrm{mTc}-\mathrm{HMPAO}$, and ${ }^{123}$ I-IMP can enter into brain cells through the normal blood-brain barrier 

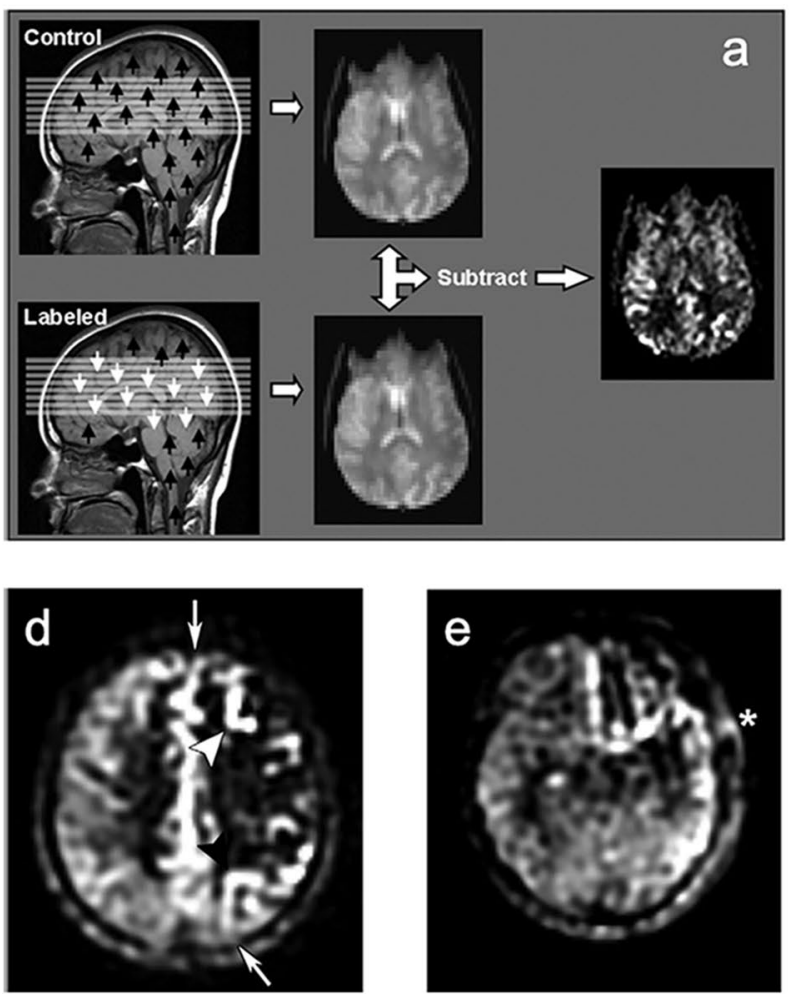

Fig. 5 Arterial spin-labeled MRI in moyamoya disease. a Blood proton from the ICA was labeled once (labeled) and twice (controlled) by $180^{\circ}$ radiofrequency pulse, respectively. After T1 delay, the protons arrived at the signal acquisition area, and the labeled image and control image were obtained respectively. After subtraction of these two images, a difference image with intensity proportional to cerebral blood flow (CBF) was obtained, i.e., cerebral perfusion image. b, c ASL sequences of a moyamoya patient with good recovery after bilateral bypass surgery. The preoperative ASL (b) signal (arrows) war dark, indicating markedly reduced perfusion to bilateral MCA territories. The postoperative image (c) shows increased ASL signal in the bilateral MCA territories (arrows). d, e ASL sequences of a moyamoya patient with poor recovery after left bypass surgery. Preopera-

and can be used to assess the regional brain function. A hypo-responsive CVR on postoperative basal or acetazolamide-challenged SPECT in patients with MMD suggests a poor prognosis such as remaining neurological deficits and ischemic attacks during follow-up [65]. Association of cognitive dysfunction with improvement with $\mathrm{CBF}$ changes measured by SPECT has been explored both in adult and pediatric patients with MMD [32,69].

Yanagihara et al. [74] recently found that CHS in the acute stage after bypass surgery impairs cognitive function and that an increase in CBF in the chronic stage improves cognitive function in adult patients with symptomatic ischemic MMD and misery perfusion.
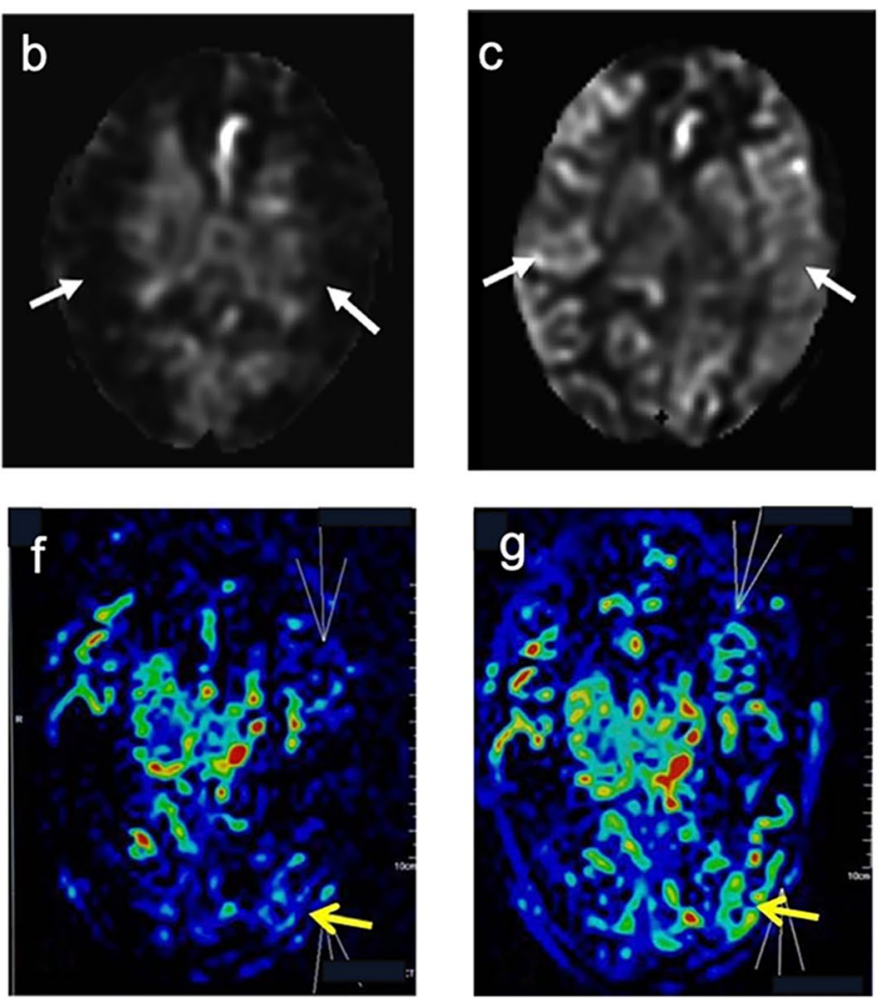

tive ASL images (d) show decreased perfusion (arrows) and arterial transit artifact (ATA) signals in left distal ICA territories (arrowheads) indicating late-arriving flow via collateral pathways. After left MCA-STA bypass surgery, postoperative ASL images (e) still show impaired perfusion and ATA signals in left MCA territory and prominent ATA signal in MCA-STA anastomosis site $(*)$ indicating flow stagnation in anastomosis site. $\mathbf{f}, \mathbf{g}$ Color-coded ASL perfusion images of a moyamoya patient who had moderate to severe headache with seizures at the second postoperative day, and was clinically suspected as hyperperfusion syndrome. There was a significantly raised perfusion (more than $100 \%$ increase in CBF values) in the left occipital regions (yellow arrows) between preoperative (f) and postoperative (g) $[39,49,56,72]$

\section{Positron emission tomography (PET)}

PET is considered the standard functional imaging method for quantifying metabolic processes that are relevant to MMD vascular functionalities after bypass surgery. $\mathrm{H}_{2}{ }^{15} \mathrm{O}$, ${ }^{15} \mathrm{O}_{2}$, and $\mathrm{C}^{15} \mathrm{O}_{2}$ are commonly used as tracers in PET for cerebral hemodynamic assessments. The oxygen extraction fraction (OEF) and cerebral metabolic rate of oxygen $\left(\mathrm{CMRO}_{2}\right)$ are important parameters for making treatment decisions in MMD and are closely related to CVRC, hemodynamic stress distribution, and characteristic features of collateralization [23]. $\mathrm{H}_{2}{ }^{15} \mathrm{O}$ PET enabled detection of impaired CVRC in a large number of symptomatic MMD patients who had negative findings on ${ }^{99} \mathrm{mTc}-\mathrm{HMPAO}$ SPECT in Acker's study [1]. Kaku et al. [27] revealed that symptomatic CHS in patients with MMD could be characterized by temporary increases in $\mathrm{CBF}>100 \%$ over 
the preoperative values, and among the preoperative PET parameters, increased OEF was the only significant risk factor for CHS. Recently, $\mathrm{H}_{2}{ }^{15} \mathrm{O}$ PET has been used for the preoperative assessment of neuropsychological impairment by measuring territorial CVR, and ${ }^{15} \mathrm{O}$ PET has been used to investigate the improvement in cognitive decline by measuring changes in OEF and $\mathrm{CMRO}_{2}$ following indirect bypass surgery $[19,57]$. These advances will be more conducive to obtaining more accurate information through PET imaging to select MMD patients who can benefit the most from surgery. However, PET is limited by its general clinical unavailability, high cost, and lengthy measurement time.

\section{Fluorescence imaging}

Indocyanine green and sodium fluorescein are commonly used imaging agents for intraoperative fluorescence imaging. With the help of Flow Insight software ${ }^{\circledR}$ (Carl Zeiss, Co.) or Flow 800 software, the direction of blood flow can be "visualized." The direction of blood flow after bypass is related to the pressure difference between donor and recipient vessels, and the watershed migration can occur, suggesting the dysfunction of the cortical cerebral hemodynamics. Intraoperative fluorescence imaging provides semiquantitative regional hemodynamic alterations and can be used to identify patients at high risk of transient neurological events; thus, the perioperative treatment can be adjusted (Fig. 6) [69, 75, 76]. Horie et al. [21] found that the mismatch ratio of donor STA/recipient MCA and poor run-off or stagnation of blood flow from the STA might contribute to postoperative CHS in patients with MMD.

Another similar optical imaging technique is microscopic cortical venous redness (venous reddening). This digital photographic method is based on intraoperative measurement of venous oxygen saturation by venous $R$ intensity, which can indirectly represent tissue oxygen metabolism and CBF impairment, and is of great value in detection of CHS immediately after anastomosis [45, 46].

\section{Ultrasonography (US)}

\section{Transcranial color-coded duplex sonography (TCCS)}

TCCS can provide in real-time quantitative information on donor and recipient arteries, which is an ideal imaging tool to monitor graft flow postoperatively [77, 79]. Quantitative parameters such as peak-systolic velocity (PSV), a

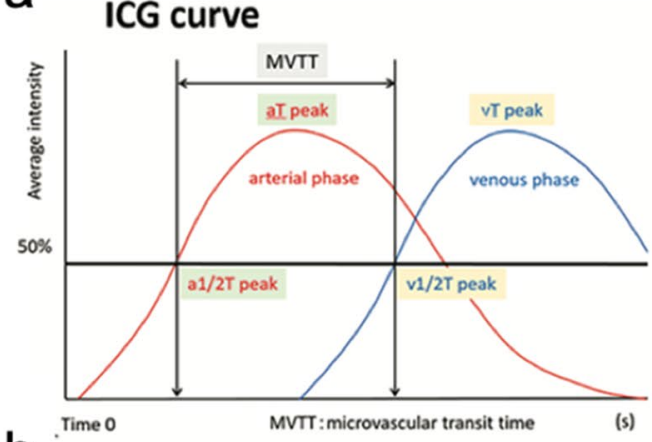

b

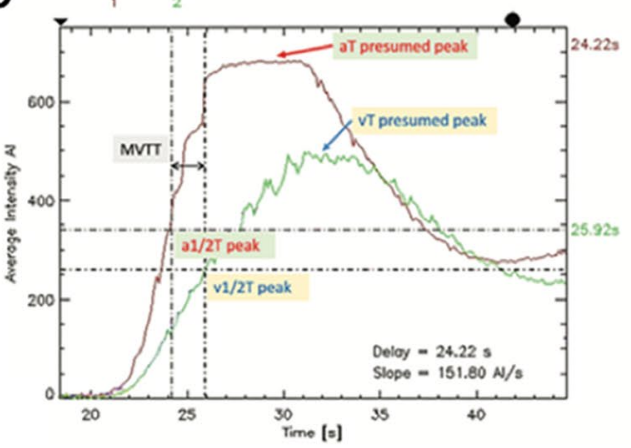

C

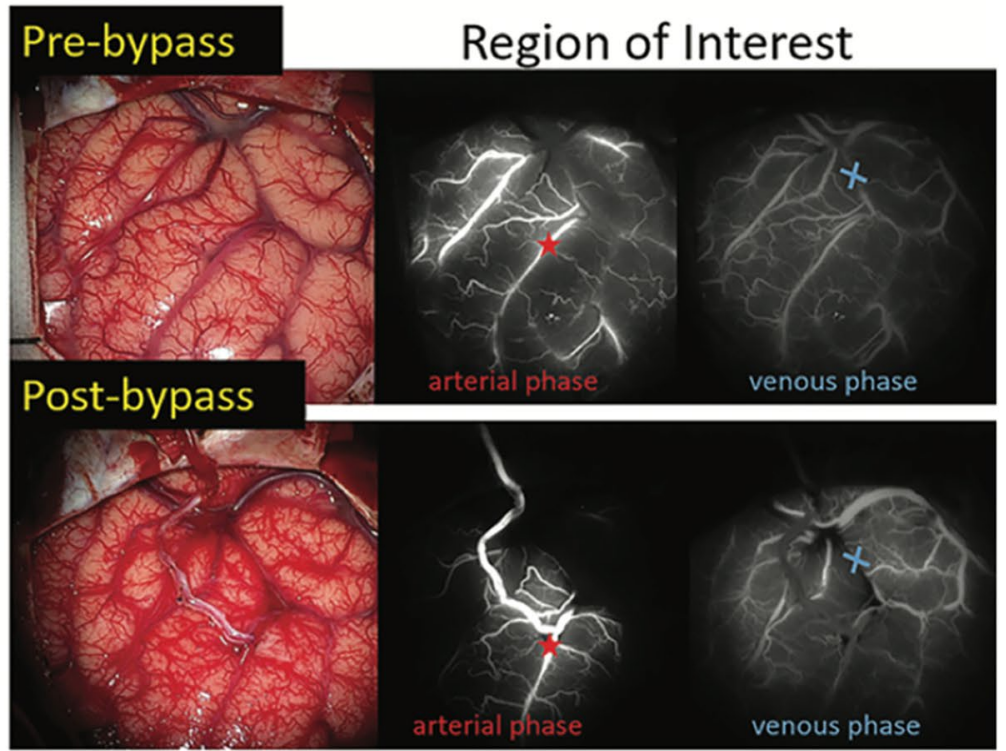

Fig. 6 Morphological visualization and quantitative assessment of STA-MCA bypass in MMD by ICG with FLOW 800 software. a Microvascular transit time (MVTT) was calculated as venous $\mathrm{T}_{1 / 2}$ peak-arterial $\mathrm{T}_{1 / 2}$ from ICG time intensity curve. b The "time to half-value of peak" ( $\mathrm{T}_{1 / 2}$ peak) was used instead of "time to peak," because the "time to peak" was difficult to define. c Analysis of the ICG time intensity curve was performed on the same ROIs in arterial phase (asterisk) and venous phase (cross) respectively before and after bypass surgery [75] 

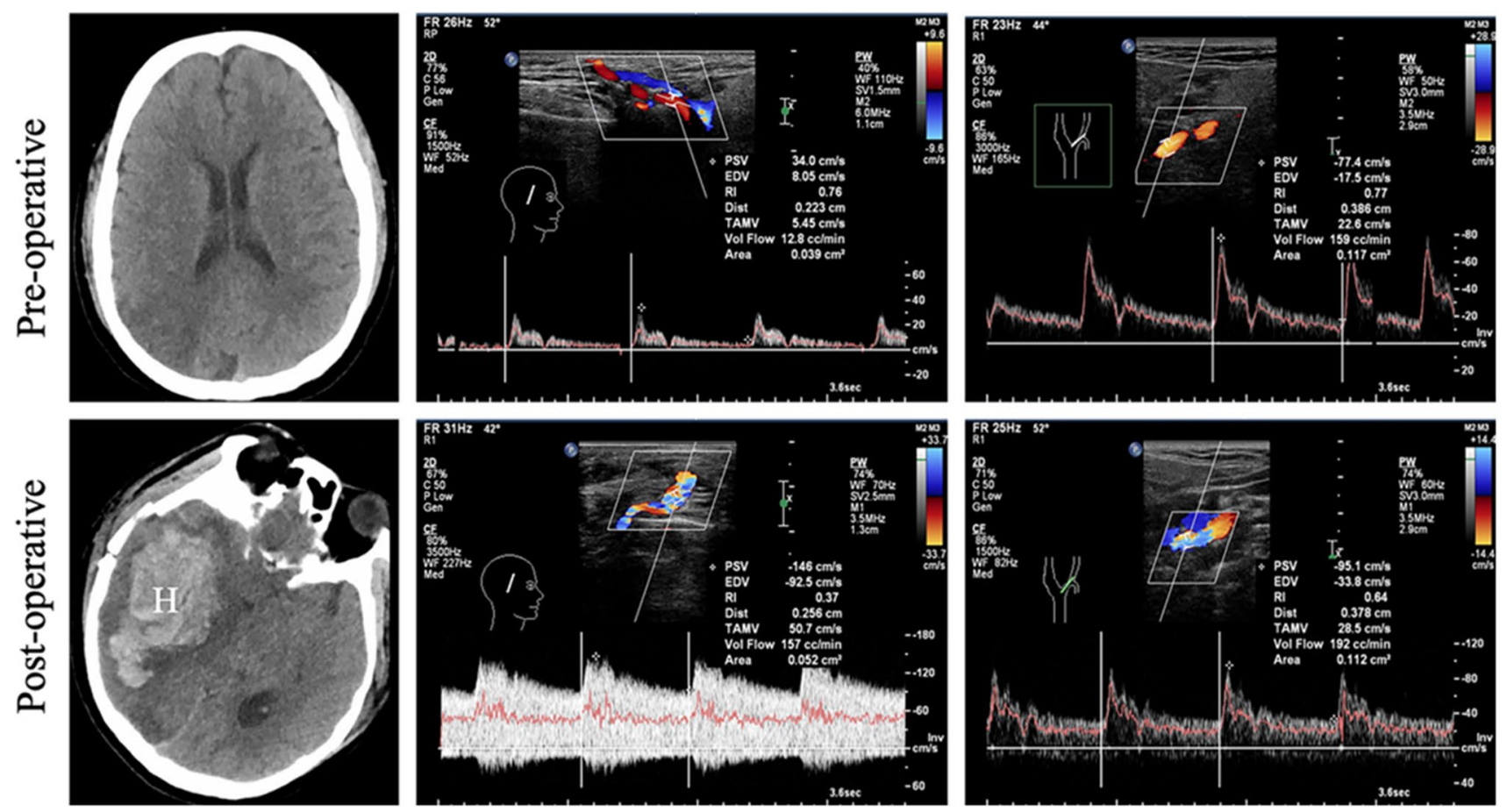

Fig. 7 A 44-year-old male MMD patient underwent right-side STAMCA bypass surgery. One week after, the patient was found CHS manifesting with headache, vomiting, and consciousness disturbance. Emergency CT showed a large hematoma in the right frontotemporal insular lobe, complicated with basal ganglia hemorrhage and cerebral hernia (the left column). On TCCS, PSV at the proximal end of STA increased sharply more than 4 folds, RI decreased by half (the middle column), and the flow velocity of ECA slightly increased (the right column). H indicates hematoma; CHS, cerebral hyper-perfusion syndrome. Image courtesy of Dr. Chenyun Zhou, Department of Ultrasound, West China Hospital

imaging can not only help to effectively identify recipient artery before anastomosis effectively, but also help to check the flow velocity and direction of blood flow after bypass surgery, characterizing hemodynamic status [48, 53].

\section{Transcranial Doppler (TCD)}

TCD is a commonly used clinical tool for monitoring intracranial ischemic diseases in neurology department because of its characteristics of non-invasive, quick, bedside, and cheap. Cerebral vasomotor reactivity (VMR) measured by TCD can reflect cerebrovascular reserve, providing an important reference for preoperative hemodynamic assessment [26]. In cases of stenosis of terminal ICA, TCD showed abnormally elevated blood flow velocity and increased PI at the stenosis site, presenting eddy current spectrum. When an artery occlusion occurs, the flow velocity is slow and the spectrum changes into a wavy pattern. In the late stage of moyamoya disease, the blood flow velocity of ECA and its branches increased significantly, and the morphology of intracranial blood flow spectrum changed accordingly. 
Table 1 Comparison of imaging modalities used in revascularization of moyamoya disease

\begin{tabular}{|c|c|c|c|c|c|c|}
\hline \multirow[t]{2}{*}{ Imaging modality } & \multirow{2}{*}{$\begin{array}{l}\text { Main roles in MMD revascu- } \\
\text { larization }\end{array}$} & \multirow{2}{*}{$\begin{array}{l}\text { Hemodynamic evaluation } \\
\text { (Quantitative parameters) }\end{array}$} & \multicolumn{3}{|c|}{ Applicable scenario } & \multirow[t]{2}{*}{ Contrast materials and Tracers } \\
\hline & & & Pre-op & Intra-op & Post-op & \\
\hline DSA & $\begin{array}{l}\text { - Gold standard for MMD } \\
\text { diagnosis and grading [44] } \\
\text {-Proof of patency of EC-IC } \\
\text { bypass [15] } \\
\text {-Presentation of the collat- } \\
\text { eral circulation [14, 43] } \\
\text {-Identification of concomi- } \\
\text { tant diseases }[4,42,50]\end{array}$ & MTT, TTP, AUC & +++ & + & ++ & Iodinated contrast agents \\
\hline CT & $\begin{array}{l}\bullet \text { Emergency situations } \\
\text {-Visualization of abnormal } \\
\text { basal vascular network and } \\
\text { MCA cortical arteries [66] } \\
\text {-Evaluation of postoperative } \\
\text { cerebral perfusion recov- } \\
\text { ery }[7,10,29,65]\end{array}$ & CBV, CBF, MTT, TTP & +++ & + & +++ & Iodinated contrast agents \\
\hline MRI & $\begin{array}{l}\text {-Monitoring of intracra- } \\
\text { nial artery stenosis and } \\
\text { ischemic changes [27] } \\
\text {-Intracranial vessel wall } \\
\text { imaging [60, 73, 82] } \\
\text { - Better display of MMVs } \\
\text { on ultrahigh field intensity } \\
\text { MRI [12, 34, 62, 63] } \\
\text {-Evaluation of postoperative } \\
\text { hemodynamic recovery } \\
\text { or dysfunction }[18,24, \\
25,49] \\
\text {-Assessment of surgical } \\
\text { efficacy and prediction of } \\
\text { patients' prognosis [59, 61] }\end{array}$ & CBV, CBF, MTT, TTP, CVR & +++ & + & +++ & $\begin{array}{l}\text { Exogenous material: Gado- } \\
\text { linium chelate (DSC-MRI); } \\
\text { Endogenous material: Arterial } \\
\text { water proton (ASL-MRI), } \\
\text { Deoxyhemoglobin (BOLD- } \\
\text { fMRI) }\end{array}$ \\
\hline SPECT & $\begin{array}{l}\text {-The reference standard for } \\
\text { cerebral perfusion }[16,64]\end{array}$ & $\mathrm{CBF}, \mathrm{CBV}, \mathrm{CVR}$ & ++ & - & ++ & $\begin{array}{l}{ }^{99} \mathrm{mTc}-\mathrm{HMPAO}, \\
{ }^{99} \mathrm{mTc}-\mathrm{ECD},{ }^{123} \mathrm{I} \text {-IMP }\end{array}$ \\
\hline PET & $\begin{array}{l}\text {-Metabolic assessment of } \\
\text { brain tissue [23] } \\
\text {-Assessment of neuropsy- } \\
\text { chological impairment and } \\
\text { recovery }[19,57]\end{array}$ & $\begin{array}{l}\mathrm{CBV}, \mathrm{CBF}, \mathrm{OEF}, \mathrm{CMRO}_{2}, \\
\text { CVRC }\end{array}$ & ++ & - & ++ & ${ }^{15} \mathrm{O}_{2}, \mathrm{C}^{15} \mathrm{O}_{2}, \mathrm{H}_{2}{ }^{15} \mathrm{O}$ \\
\hline Fluorescence imaging & $\begin{array}{l}\bullet \text { Real-time imaging of } \\
\text { bypass, and direct monitor- } \\
\text { ing of blood flow }[69,75 \text {, } \\
76]\end{array}$ & MTT, TTP, AUC & - & +++ & - & $\begin{array}{l}\text { Indocyanine green, } \\
\text { Sodium fluorescein }\end{array}$ \\
\hline US & $\begin{array}{l}\bullet \text { Quantification of blood } \\
\text { flow of donor, recipient, } \\
\text { and bypass arteries [2, } \\
\text { 77-79] } \\
\text {-Intraoperative navigation } \\
{[48,53]} \\
\text {-Cerebral vasomotor reac- } \\
\text { tivity assessment [26] } \\
\text { •Mapping of cerebral vascu- } \\
\text { lar circulation [54] }\end{array}$ & PSV, EDV, PI, RI & ++ & +++ & +++ & $\begin{array}{l}\text { None (TCCS, TCD) } \\
\text { Microbubbles(CEUS) }\end{array}$ \\
\hline
\end{tabular}

$D S A$, digital subtraction angiography; $C T$, computed tomography; $M R I$, magnetic resonance imaging, ICG-VAG, indocyanine green video-angiography; US, ultrasonography; SPECT, single-photon emission computed tomography; PET, positron emission tomography; TCCS, transcranial color-coded duplex sonography; TCD, transcranial Doppler; CEUS, contrast-enhanced ultrasound. Pre-op, preoperative; Intra-op, intraoperative; Post-op, postoperative; $A U C$, area under the curve; $C V R$, cerebral vascular reserve; $C V R C$, cerebrovascular reserve capacity; $O E F$, oxygen extraction fraction; $\mathrm{CMRO}_{2}$, cerebral metabolic rate of oxygen; $M T T$, mean transit time; TTP, time to peak; $A U C$, area under the curve; PSV, peak-systolic velocity; $E D V$, end-diastolic velocity; $P I$, pulsatility index; $R I$, resistance index

“+ + +" highly recommended; “+ +" recommended; “+” moderately recommended; "“” less recommended 


\section{Contrast-enhanced ultrasound (CEUS)}

CEUS is a promising imaging technique for visualizing microvascular circulation and brain perfusion with qualitative and semi-quantitative information. CEUS has been used to assess neurosurgical conditions such as intracranial tumors, arteriovenous malformations, and aneurysms [33, 36]. The application of CEUS in evaluating MMD revascularization is not well known to neurosurgeons. In a recent rat model of MCA occlusion, transcranial CEUS revealed striking decreases in cortical and striatal blood volume, flow velocity, and cerebral perfusion during ischemic stroke. After vessel recanalization, blood volume and perfusion increased twofold above the baseline value, which is indicative of acute CHS [54]. This study mimics the mechanism of surgical bypass of MMD, which lays a foundation for the future intraoperative CEUS evaluations in human MMD.

\section{Discussion}

Moyamoya disease is a potential risk factor for stroke. Complex vascular remodeling, whether due to disease progression or surgical intervention, leads to changes in cerebral morphology, hemodynamics, and clinical improvements or complications. Early detection of these changes and their concomitant effects is the key to the treatment of moyamoya disease. Table 1 compares and discusses the main roles and applicable scenarios of each imaging modality in revascularization of moyamoya disease. In pre-operative period, DSA is still considered the gold standard for diagnosis and grading up to now; however, in pediatric patients or patients with generally poor conditions, MRA or CTA may be an alternative. In intraoperative period, fluorescence imaging and IVUS are superior in real-time monitoring of blood flow in a certain artery. It is recommended that regular hemodynamic assessment by TCCS examination should be performed regularly at 1 week, 1 month, 3 months, 6 months, and 1 year after surgery, and CTP examination should be carried out half a year after the operation. Patients with unilateral moyamoya disease should undergo CTA or MRA once a year to evaluate disease progression. DSA could be carried out if there are new neurological symptoms. SPECT and PET are not currently necessary because they are expensive but can be used conditionally.

\section{Summary}

Neuroimaging can assist surgeons to optimize matching selection of donor-recipient arteries, prevent the occurrence of postoperative perfusion disorders, and improve the accuracy of bypass as much as possible. In recent years, the rapid development of imaging technology, such as MRI and ultrasound, with their advantages of radiation-free, fast, and low cost, plays an increasingly important role in the diagnosis and treatment of moyamoya disease, especially in pediatrics.

Author contribution Idea for the article: Yan Feng, Du Lanxin; Literature search and data analysis: Yan Feng, Du Lanxin; Methodology: Guo Yingkun, Li Jin, Zhou Chenyun; Writing — original draft preparation: Du Lanxin; Writing — review and editing: Yan Feng, Du Lanxin, Guo Yingkun, Zhou Chenyun.

Data availability Not applicable.

Code availability Not applicable.

\section{Declarations}

Ethics approval The nature of this study does not require approval by the ethical committees. The study followed the Declaration of Helsinki (64th WMA General Assembly, Fortaleza, Brazil, October 2013).

Informed consent Informed consent was abandoned in this study because sensitive patient-related information was not involved.

Consent to participate Written informed consent for participation was obtained from all authors.

Consent for publication Written informed consent for publication was obtained from all authors.

Conflict of interest The authors declare no competing interests.

Open Access This article is licensed under a Creative Commons Attribution 4.0 International License, which permits use, sharing, adaptation, distribution and reproduction in any medium or format, as long as you give appropriate credit to the original author(s) and the source, provide a link to the Creative Commons licence, and indicate if changes were made. The images or other third party material in this article are included in the article's Creative Commons licence, unless indicated otherwise in a credit line to the material. If material is not included in the article's Creative Commons licence and your intended use is not permitted by statutory regulation or exceeds the permitted use, you will need to obtain permission directly from the copyright holder. To view a copy of this licence, visit http://creativecommons.org/licenses/by/4.0/.

\section{References}

1. Acker G, Lange C, Schatka I et al (2018) Brain perfusion imaging under acetazolamide challenge for detection of impaired cerebrovascular reserve capacity: positive findings with O-15-water PET in patients with negative Tc-99m-HMPAO SPECT findings. J Nucl Med 59(2):294-298. https://doi.org/10.2967/jnumed.117. 195818

2. Adla T, Adlova R (2015) Multimodality imaging of carotid stenosis. Int J Angiol 24(3):179-184. https://doi.org/10.1055/s-00351556056

3. Alnemari A, Mansour TR, Bazerbashi M, Buehler M, Schroeder J, Gaudin D (2017) Dynamic four-dimensional computed tomography angiography for neurovascular pathologies. World Neurosurgery 105:1034.e11-1034.e18. https://doi.org/10.1016/j.wneu. 2017.06.022 
4. Bechan RS, van Rooij SB, Sprengers ME et al (2015) CT angiography versus $3 \mathrm{D}$ rotational angiography in patients with subarachnoid hemorrhage. Neuroradiology 57(12):1239-1246. https://doi. org/10.1007/s00234-015-1590-9

5. Blauwblomme T, Lemaitre H, Naggara O et al (2016) Cerebral blood flow improvement after indirect revascularization for pediatric moyamoya disease: a statistical analysis of arterial spinlabeling MRI. Am J Neuroradiol 37(4):706-712. https://doi.org/ 10.3174/ajnr.A4592

6. Chen Q, Qi R, Cheng X et al (2014) Assessment of extracranial-intracranial bypass in Moyamoya disease using 3T time-offlight MR angiography: comparison with CT angiography. Vasa 43(4):278-283. https://doi.org/10.1024/0301-1526/a000363

7. Chen Y, Xu W, Guo X et al (2016) CT perfusion assessment of moyamoya syndrome before and after direct revascularization (superficial temporal artery to middle cerebral artery bypass). Eur Radiol 26(1):254-261. https://doi.org/10.1007/ s00330-015-3802-4

8. Chen Y, Ma L, Yang S et al (2020) Quantitative angiographic hemodynamic evaluation after revascularization surgery for moyamoya disease. Transl Stroke Res 11(5):871-881. https://doi.org/ 10.1007/s12975-020-00781-5

9. Cho HH, Cheon JE, Kim SK et al (2016) Quantitative assessment of neovascularization after indirect bypass surgery: color-coded digital subtraction angiography in pediatric moyamoya disease. AJNR Am J Neuroradiol 37(5):932-8. https://doi.org/10.3174/ ajnr.A4614

10. Dai DW, Zhao WY, Zhang YW et al (2013) Role of CT perfusion imaging in evaluating the effects of multiple burr hole surgery on adult ischemic moyamoya disease. Neuroradiology 55(2):14311438. https://doi.org/10.1007/s00234-013-1291-1

11. Dlamini N, Shah-Basak P, Leung J et al (2018) Breath-hold blood oxygen level-dependent MRI: a tool for the assessment of cerebrovascular reserve in children with moyamoya disease. Am J Neuroradiol 39(9):1717-1723. https://doi.org/10.3174/ajnr.A5739

12 Deng X, Zhang Z, Zhang Y et al (2015) Comparison of 7.0- and 3.0-T MRI and MRA in ischemic-type moyamoya disease: preliminary experience. J Neurosurg 124(6):1716-25. https://doi.org/ 10.3171/2015.5.JNS15767

13. Fan AP, Guo J, Khalighi MM et al (2017) Long-delay arterial spin labeling provides more accurate cerebral blood flow measurements in moyamoya patients a simultaneous positron emission tomography/MRI study. Stroke 48(9):2441-2449. https://doi.org/ 10.1161/STROKEAHA.117.017773

14. Ge $P$, Zhang Q, Ye X et al (2020) Digital subtraction angiographic characteristics of progression of moyamoya disease 6 months prior to surgical revascularisation. Stroke Vasc Neurol 5(1):97102. https://doi.org/10.1136/svn-2019-000316

15 Ge P, Zhang Q, Ye X et al (2020) Postoperative collateral formation after indirect bypass for hemorrhagic moyamoya disease. BMC Neurol 20(1):28. https://doi.org/10.1186/ s12883-020-1612-Z

16. Goetti R, O'Gorman R, Khan N, Kellenberger CJ, Scheer I (2013) Arterial spin labelling MRI for assessment of cerebral perfusion in children with moyamoya disease: comparison with dynamic susceptibility contrast MRI. Neuroradiology 55(5):639-647. https:// doi.org/10.1007/s00234-013-1155-8

17. Goetti R, Warnock G, Kuhn FP et al (2014) Quantitative cerebral perfusion imaging in children and young adults with moyamoya disease: comparison of arterial spin-labeling-MRI and $\mathrm{H}(2)$ [O-15]-PET. Am J Neuroradiol 35(5):1022-1028. https://doi.org/ 10.3174/ajnr.A3799

18. Ha JY, Choi YH, Lee S et al (2019) Arterial spin labeling MRI for quantitative assessment of cerebral perfusion before and after cerebral revascularization in children with moyamoya disease.
Korean J Radiol 20(6):985-996. https://doi.org/10.3348/kjr.2018. 0651

19. Hara S, Kudo T, Hayashi $S$ et al (2020) Improvement in cognitive decline after indirect bypass surgery in adult moyamoya disease: implication of O-15-gas positron emission tomography. Ann Nucl Med 34(7):467-475. https://doi.org/10.1007/s12149-020-01473-8

20. Hauser TK, Seeger A, Bender B et al (2019) Hypercapnic BOLD MRI compared to (H2O)-O-15 PET/CT for the hemodynamic evaluation of patients with moyamoya disease. Neuroimage Clin 22:101713. https://doi.org/10.1016/j.nicl.2019.101713

21. Horie N, Fukuda Y, Izumo T, Hayashi K, Suyama K, Nagata I (2014) Indocyanine green videoangiography for assessment of postoperative hyperperfusion in moyamoya disease. Acta Neurochir (Wien) 156(5):919-926. https://doi.org/10.1007/ s00701-014-2054-4

22. Horie N, Morikawa M, Morofuji Y et al (2016) De novo ivy sign indicates postoperative hyperperfusion in moyamoya disease. Stroke 45(5):1488-1491. https://doi.org/10.1161/STROKEAHA. 114.004755

23. Ikezaki K, Matsushima T, Kuwabara Y, Suzuki SO, Nomura T, Fukui M (1994) Cerebral-circulation and oxygen-metabolism in childhood moyamoya disease - a perioperative positron emission tomography study. J Neurosurg 81(6):843-850. https://doi.org/10. 3171/jns.1994.81.6.0843

24. Ishii Y, Nariai T, Tanaka Y et al (2014) Practical clinical use of dynamic susceptibility contrast magnetic resonance imaging for the surgical treatment of moyamoya disease. Neurosurgery 74(3):302-309. https://doi.org/10.1227/Neu.0000000000000266

25. Ishii Y, Tanaka Y, Momose T et al (2017) Chronologic evaluation of cerebral hemodynamics by dynamic susceptibility contrast magnetic resonance imaging after indirect bypass surgery for moyamoya disease. World Neurosurgery 108:427-435. https://doi. org/10.1016/j.wneu.2017.09.001

26. Ju K, Zhong L, Ni X, Cao H, Cheng G, Ding L (2018) Cerebral vasomotor reactivity predicts the development of acute stroke in patients with internal carotid artery stenosis. Neurol Neurochir Pol May-Jun 52(3):374-378. https://doi.org/10.1016/j.pjnns. 2017.12.015

27. Kaku Y, Iihara K, Nakajima N et al (2012) Cerebral blood flow and metabolism of hyperperfusion after cerebral revascularization in patients with moyamoya disease. J Cerebr Blood F Metab 32(11):2066-2075. https://doi.org/10.1038/jcbfm.2012.110

28 Kaku Y, Iihara K, Nakajima N et al (2013) The leptomeningeal ivy sign on fluid-attenuated inversion recovery images in moyamoya disease: positron emission tomography study. Cerebrovasc Dis 36(1):19-25. https://doi.org/10.1159/000351143

29. Kang K, Ma N, Li J et al (2020) Cerebral hemodynamic changes after revascularization in patients with hemorrhagic moyamoya disease. Front Neurol 11(11):72. https://doi.org/10.3389/fneur. 2020.00072

30. Kathuveetil A, Sylaja PN, Senthilvelan S, Chandrasekharan K, Banerjee M, Sudhir BJ (2020) Vessel wall thickening and enhancement in high-resolution intracranial vessel wall imaging: a predictor of future ischemic events in moyamoya disease. Am J Neuroradiol 41(1):100-105. https://doi.org/10.3174/ajnr. A6360

31. Kawashima M, Noguchi T, Takase Y, Nakahara Y, Matsushima $\mathrm{T}$ (2010) Decrease in leptomeningeal ivy sign on fluid-attenuated inversion recovery images after cerebral revascularization in patients with moyamoya disease. Am J Neuroradiol 31(9):17131718. https://doi.org/10.3174/ajnr.A2124

32. Kazumata K, Tokairin K, Sugiyama T, et al (2019) Association of cognitive function with cerebral blood flow in children with moyamoya disease. J Neurosurg Pediatr 7:1-7. https://doi.org/10. 3171/2019.7.PEDS19312 
33. Kearns KN, Sokolowski JD, Chadwell K et al (2019) The role of contrast-enhanced ultrasound in neurosurgical disease. Neurosurg Focus 47(6):E8. https://doi.org/10.3171/2019.9.FOCUS19624

34. Kong Q, Zhang Z, Yang Q et al (2019) 7T TOF-MRA shows modulated orifices of lenticulostriate arteries associated with atherosclerotic plaques in patients with lacunar infarcts. Eur J Radiol 118:271-276. https://doi.org/10.1016/j.ejrad.2019.07.032

35. Kim SH, Lee H, Yoo M et al (2019) Angiographic and clinical outcomes of non-patent anastomosis after bypass surgery in adult moyamoya disease. Acta Neurochir (Wien) 161(2):379-384. https://doi.org/10.1007/s00701-018-3733-3

36. Knieling F, Rüffer A, Cesnjevar R et al (2020) Transfontanellar contrast-enhanced ultrasound for monitoring brain perfusion during neonatal heart surgery. Circ Cardiovasc Imaging 13(3):e010073. https://doi.org/10.1161/CIRCIMAGING.119. 010073

37. Kuroda S, Houkin K (2008) Moyamoya disease: current concepts and future perspectives. Lancet Neurol 7(11):1056-1066. https:// doi.org/10.1016/S1474-4422(08)70240-0

38. Lee M, Guzman R, Bell-Stephens T, Steinberg GK (2011) Intraoperative blood flow analysis of direct revascularization procedures in patients with moyamoya disease. J Cerebr Blood F Met 31(1):262-274. https://doi.org/10.1038/jcbfm.2010.85

39. Lee S, Yun TJ, Yoo RE et al (2018) (2018) Monitoring cerebral perfusion changes after revascularization in patients with moyamoya disease by using arterial spin-labeling MR imaging. Radiology 288(2):565-572. https://doi.org/10.1148/radiol.2018170509

40. Lee SU, Oh CW, Kwon OK et al (2018) Surgical treatment of adult moyamoya disease. Curr Treat Options Neurol 20(7):22. https://doi.org/10.1007/s11940-018-0511-8

41. Liu P, Li Y, Pinho M, Park DC, Welch BG, Lu H (2017) Cerebrovascular reactivity mapping without gas challenges. Neuroimage 146:320-326. https://doi.org/10.1016/j.neuroimage.2016.11.054

42 Liu P, Lv XL, Liu AH et al (2016) Intracranial aneurysms associated with moyamoya disease in children: clinical features and long-term surgical outcome. World Neurosurg 94:513-520. https://doi.org/10.1016/j.wneu.2016.05.039

43. Liu ZW, Han C, Zhao F et al (2019) Collateral circulation in moyamoya disease: a new grading system. Stroke 50(10):27082715. https://doi.org/10.1161/STROKEAHA.119.024487

44. Fukui M (1997) Guidelines for the diagnosis and treatment of spontaneous occlusion of the circle of Willis ('moyamoya' disease). Research committee on spontaneous occlusion of the circle of willis (Moyamoya Disease) of the ministry of health and welfare, Japan. Clin Neurol Neurosurg 99 Suppl 2N:S238-S240

45. Machida T, Higuchi Y, Nakano S et al (2017) Cortical venous redness represents tissue circulation status in patients with moyamoya disease. Stroke 48(6):1665-1667. https://doi.org/ 10.1161/STROKEAHA.116.015991

46. Machida T, Ono J, Nomura R, Fujikawa A, Nagano O, Higuchi $\mathrm{Y}$ (2014) Venous reddening as a possible sign of hyperperfusion after superficial temporal artery-middle cerebral artery anastomosis for moyamoya disease: case report. Neurol Med Chir (Tokyo) 54(10):827-831. https://doi.org/10.2176/nmc.cr. 2013-0261

47 Mandell DM, Mossa-Basha M, Qiao Y et al (2017) Vessel Wall Imaging Study Group of the American Society of Neuroradiology. Intracranial Vessel Wall MRI: Principles and Expert Consensus Recommendations of the American Society of Neuroradiology. Am J Neuroradiol 38(2):218-229. https://doi.org/10.3174/ajnr. A4893

48. Morisawa H, Kawamata T, Kawashima A et al (2013) Hemodynamics and changes after STA-MCA anastomosis in moyamoya disease and atherosclerotic cerebrovascular disease measured by micro-Doppler ultrasonography. Neurosurg Rev 36(3):411-419. https://doi.org/10.1007/s10143-012-0441-y
49. Agarwal V, Singh P, Ahuja CK, Gupta SK, Aggarwal A, Narayanan R (2021) Non-invasive assessment of cerebral microvascular changes for predicting postoperative cerebral hyperperfusion after surgical revascularisation for moyamoya disease: an arterial spin labelling MRI study. Neuroradiology 63(4):563-572. https://doi. org/10.1007/s00234-020-02583-w

50 Ni W, Jiang H, Xu B et al (2018) Treatment of aneurysms in patients with moyamoya disease: a 10-year single-center experience. J Neurosurg 128(6):1813-1822. https://doi.org/10.3171/ 2017.3.JNS162290

51. Noguchi T, Kawashima M, Irie H et al (2011) Arterial spin-labeling MR imaging in moyamoya disease compared with SPECT imaging. Eur J Radiol 80(3):e557-e562. https://doi.org/10.1016/j. ejrad.2011.01.016

52. Noguchi T, Kawashima M, Nishihara M, Egashira Y, Azama S, Irie H (2015) Noninvasive method for mapping CVR in moyamoya disease using ASL-MRI. Eur J Radiol 84(6):1137-1143. https://doi.org/10.1016/j.ejrad.2015.03.011

53. Nomura M, Tamase A, Kamide $T$ et al (2017) Pin-point selection of recipient MCA at M4 for STA-MCA bypass using microDoppler ultrasonography. J Neurosurg Sci 61(4):446-449. https:// doi.org/10.23736/S0390-5616.16.03381-6

54. Premilovac D, Blackwood SJ, Ramsay CJ, Keske MA, Howells DW, Sutherland BA (2020) Transcranial contrast-enhanced ultrasound in the rat brain reveals substantial hyperperfusion acutely post-stroke. J Cereb Blood Flow Metab 40(5):939-953. https:// doi.org/10.1177/0271678X20905493

55. Qiao PG, Han C, Zuo ZW et al (2017) Clinical assessment of cerebral hemodynamics in Moyamoya disease via multiple inversion time arterial spin labeling and dynamic susceptibility contrastmagnetic resonance imaging: A comparative study. J Neuroradiology 44(4):273-280. https://doi.org/10.1016/j.neurad.2016.12.006

56. Quon JL, Kim LH, Lober RM, Maleki M, Steinberg GK, Yeom KW (2019) Arterial spin-labeling cerebral perfusion changes after revascularization surgery in pediatric moyamoya disease and syndrome. J Neurosurg Pediatr 23(4):486-492. https://doi. org/10.3171/2018.11.PEDS18498

57. Roder C, Haas P, Fudali M, et al (2020) Neuropsychological impairment in adults with moyamoya angiopathy: preoperative assessment and correlation to MRI and H215O PET. Neurosurg Rev 43(6):1615-1622. https://doi.org/10.1007/ s10143-019-01192-3

58. Roder C, Hauser TK, Ernemann U, Tatagiba M, Khan N, Bender B (2019) Arterial wall contrast enhancement in progressive moyamoya disease. J Neurosurg 132(6):1845-1853. https://doi.org/ 10.3171/2019.2.JNS19106

59. Rosen C, McKetton L, Russell J et al (2018) Long-term changes in cerebrovascular reactivity following EC-IC bypass for intracranial steno-occlusive disease. J Clin Neurosci 54:77-82. https://doi.org/ 10.1016/j.jocn.2018.06.009

60. Ryoo S, Cha J, Kim SJ et al (2014) High-resolution magnetic resonance wall imaging findings of moyamoya disease. Stroke 45(8):2457-2460. https://doi.org/10.1161/STROKEAHA.114. 004761

61. Sam K, Poublanc J, Sobczyk O et al (2015) Assessing the effect of unilateral cerebral revascularisation on the vascular reactivity of the non-intervened hemisphere: a retrospective observational study. BMJ Open 5(2):e006014. https://doi.org/10.1136/bmjop en-2014-006014

62. Suzuki T, Natori T, Sasaki M et al (2020) Evaluating recanalization of relevant lenticulostriate arteries in acute ischemic stroke using high-resolution MRA at 7T. Int J Stroke 19:1747493019897868. https://doi.org/10.1177/1747493019 897868

63 Su J, Ni W, Yang B et al (2021) Preliminary study on the application of ultrahigh field magnetic resonance in moyamoya disease. 
Oxid Med Cell Longev 2021:5653948. https://doi.org/10.1155/ 2021/5653948

64. Setta K, Kojima D, Shimada Y et al (2018) Accuracy of brain perfusion single-photon emission computed tomography for detecting misery perfusion in adult patients with symptomatic ischemic moyamoya disease. Ann Nucl Med 32(9):611-619. https://doi.org/ 10.1007/s12149-018-1283-7

65. So Y, Lee HY, Kim SK, Lee JS et al (2005) Prediction of the clinical outcome of pediatric moyamoya disease with postoperative basal/acetazolamide stress brain perfusion SPECT after revascularization surgery. Stroke 36(7):1485-1489. https://doi.org/10. 1161/01.STR.0000170709.95185.b1

66. Suzuki H, Mikami T, Komatsu K et al (2017) Assessment of the cortical artery using computed tomography angiography for bypass surgery in moyamoya disease. Neurosurg Rev 40(2):299_ 307. https://doi.org/10.1007/s10143-016-0773-0

67. Tian B, Xu B, Liu Q, Hao Q, Lu J (2013) Adult Moyamoya disease: 320-multidetector row CT for evaluation of revascularization in STA-MCA bypasses surgery. Eur J Radiol 82(12):2342-2347. https://doi.org/10.1016/j.ejrad.2013.09.006

68. Uchino H, Yamamoto S, Kashiwazaki D, et al (2019) Using postoperative remodeling of donor arteries on MR angiography to predict the development of surgical collaterals in moyamoya disease. J Neurosurg 8:1-9. https://doi.org/10.3171/2019.8.JNS191846

69. Uda K, Araki Y, Muraoka S et al (2019) Intraoperative evaluation of local cerebral hemodynamic change by indocyanine green videoangiography: prediction of incidence and duration of postoperative transient neurological events in patients with moyamoya disease. J Neurosurg 130:1367-1375. https://doi.org/10.3171/2017. 10.JNS171523

70. Wang R, Yu SL, Alger JR et al (2014) Multi-delay arterial spin labeling perfusion MRI in moyamoya disease-comparison with CT perfusion imaging. Eur Radiol 24(5):1135-1144. https://doi. org/10.1007/s00330-014-3098-9

71. Weber J, Veith P, Jung B et al (2015) MR angiography at 3 tesla to assess proximal internal carotid artery stenoses: contrast-enhanced or 3D time-of-flight MR angiography? Clin Neuroradiol 25(1):4148. https://doi.org/10.1007/s00062-013-0279-x

72 Wolf RL, Detre JA (2007) Clinical neuroimaging using arterial spin-labeled perfusion magnetic resonance imaging. Neurotherapeutics 4(3):346-59. https://doi.org/10.1016/j.nurt.2007.04.005

73. Ya JY, Zhou D, Ding J et al (2020) High-resolution combined arterial spin labeling MR for identifying cerebral arterial stenosis induced by moyamoya disease or atherosclerosis. Ann Transl Med 8(4):87. https://doi.org/10.21037/atm.2019.12.140

74. Yanagihara W, Chida K, Kobayashi M et al (2019) Impact of cerebral blood flow changes due to arterial bypass surgery on cognitive function in adult patients with symptomatic ischemic moyamoya disease. J Neurosurg 131(6):1716-1724. https://doi. org/10.3171/2018.7.JNS18149

75. Yang T, Higashino Y, Kataoka H et al (2018) Correlation between reduction in microvascular transit time after superficial temporal artery-middle cerebral artery bypass surgery for moyamoya disease and the development of postoperative hyperperfusion syndrome. J Neurosurg 128(5):1304-1310. https://doi.org/10.3171/ 2016.11.Jns 162403

76. Ye X, Liu XJ, Ma L et al (2013) Clinical values of intraoperative indocyanine green fluorescence video angiography with Flow 800 software in cerebrovascular surgery. Chinese Med J (Engl) 126(22):4232-4237. https://doi.org/10.3760/cma.j.issn.03666999.20131649

77. Yeh SJ, Tang SC, Tsai LK et al (2016) Ultrasonographic changes after indirect revascularization surgery in pediatric patients with moyamoya disease. Ultrasound Med Biol 42(12):2844-2851. https://doi.org/10.1016/j.ultrasmedbio.2016.07.016

78. Yeh SJ, Tang SC, Tsai LK et al (2017) Color Doppler ultrasonography as an alternative tool for postoperative evaluation of collaterals after indirect revascularization surgery in Moyamoya disease. PLoS ONE 12(12):e0188948. https://doi.org/10.1371/journ al.pone. 0188948

79. Yeh SJ, Tang SC, Tsai LK et al (2018) Greater ultrasonographic changes in pediatric moyamoya patients compared with adults after indirect revascularization surgeries. J Neurosurg Pediatr 22(6):663-671. https://doi.org/10.3171/2018.6.PEDS18151

80. Yu Z, Shi X, Brohi SR, Qian H, Liu FJ, Yang Y (2017) Measurement of blood flow in an intracranial artery bypass from the internal maxillary artery by intraoperative duplex sonography. $\mathbf{J}$ Ultras Med 36(2):439-447. https://doi.org/10.7863/ultra.16.02011

81. Yu Z, Yang Y, Shi X, Qian H, Liu FJ (2017) A comparison of haemodynamics between subcranial-intracranial bypass and the traditional extracranial-intracranial bypass. Brit J Neurosurg 31(6):668-671. https://doi.org/10.1080/02688697.2017.1327015

82. Yuan M, Liu ZQ, Wang ZQ, Li B, Xu LJ, Xiao XL (2015) Highresolution MR imaging of the arterial wall in moyamoya disease. Neurosci Lett 584:77-82. https://doi.org/10.1016/j.neulet.2014. 10.021

83. Yun TJ, Sohn CH, Han MH et al (2013) Effect of delayed transit time on arterial spin labeling: correlation with dynamic susceptibility contrast perfusion magnetic resonance in moyamoya disease. Invest Radiol 48(11):795-802. https://doi.org/10.1097/RLI. 0b013e3182981137

84. Zaharchuk G, Do HM, Marks MP, Rosenberg J, Moseley ME, Steinberg GK (2011) Arterial spin-labeling MRI can identify the presence and intensity of collateral perfusion in patients with moyamoya disease. Stroke 42(9):2485-2491. https://doi.org/10. 1161/STROKEAHA.111.616466

Publisher's note Springer Nature remains neutral with regard to jurisdictional claims in published maps and institutional affiliations. 